\title{
THE MECHANISM OF THE ACTION OF IODIDES ON THE NITROGEN METABOLISM
}

\author{
By G. P. GRABFIELD, C. GRAY, B. FLOWER AND EMILY KNAPP
}

(From the Laboratory of Pharmacology in the Harvard Medical School and the Laboratory of Internal Medicine in the Boston Psychopathic Hospital)

(Received for publication March 18, 1927)

It has been shown by a number of observers that the administration of iodides both to dogs and to human beings causes an increase in the output of nitrogen in the urine. One of the earliest observers (1) working with dogs showed that this was in part at the expense of the nitrogen excreted in the feces, but that the total amount of nitrogen excreted was none the less increased. We have been able to confirm this in human beings and also in the dog. Iodine has been shown to have lytic effects on fibrous tissue of which this increased nitrogen elimination may be a manifestation. Sollman (2) too has demonstrated this lytic action on subcutaneous nodules produced by the injection of local anesthetics. Various hypotheses have been offered to explain the mechanism of this action of iodides. Inhibition of antitryptic activity of the blood has been postulated by Jobling and Peterson (3) to account for the lytic action of iodine.

In previous work from this laboratory it has been shown that in the human being there is an increase in the nitrogen excretion following the ingestion of iodides (4). It has been further shown that this increase does not change the nitrogen partition (5). It has been shown that the administration of sodium iodide for three days is accompanied by an immediate increase of 15 per cent in the nitrogen excretion in the urine, coinciding with the period of drug administration. During this period the non-protein nitrogen of the blood fell only slightly. However, when potassium iodide was administered the increased excretion of nitrogen was delayed and the non-protein nitrogen of the blood rose until the increased excretion began. Consequently this nitrogen must come from some source in the body rather than represent simple retention due to kidney impermeability 
inasmuch as the excretion continued on the same level as with sodium iodide. To follow further the course of this nitrogen is the purpose of the present experiments.

Our experiments were carried out on dogs which were fed a constant diet of whole wheat bread and milk. The latter was made from dried milk of a known and constant composition and the fluid intake was kept constant. The dogs took this diet very well, showed no diarrhea nor loss of weight. It represents 2.77 grams of nitrogen per day.

TABLE 1

Shows the daily twenty-four-hour urinary nitrogen output of dogs on a constant diet The fourth, fifth and sixth days show the effect of iodide injection

\begin{tabular}{|c|c|c|c|c|c|c|c|c|c|c|}
\hline \multirow{2}{*}{$\begin{array}{l}\text { Animal } \\
\text { number }\end{array}$} & \multirow{2}{*}{$\begin{array}{c}\text { Experi- } \\
\text { ment } \\
\text { number }\end{array}$} & \multicolumn{9}{|c|}{ Day of experiment } \\
\hline & & 1 & 2 & 3 & 4 & 5 & 6 & 7 & 8 & 9 \\
\hline & & grams & grams & grams & grams & grams & grams & grams & grams & grams \\
\hline $1-1$ & 1 & 2.0 & 2.2 & 3.1 & 3.0 & 3.4 & 3.7 & 3.6 & 3.0 & 2.6 \\
\hline $2-1$ & 2 & 2.6 & 3.5 & 2.9 & 5.0 & 4.1 & 5.8 & 3.3 & 5.2 & 5.3 \\
\hline $3-1$ & 3 & 2.3 & 2.1 & 2.8 & 2.1 & 2.6 & 2.7 & 1.7 & 2.8 & 2.3 \\
\hline $3-2$ & 4 & 2.1 & 1.8 & 2.2 & 1.9 & 2.1 & 1.9 & 1.9 & 1.7 & 1.6 \\
\hline $3-3$ & 5 & 1.8 & 1.9 & 1.8 & 1.7 & 1.4 & 1.8 & 一 & - & 一 \\
\hline $3-4$ & 6 & 1.8 & 1.7 & 1.6 & 2.2 & 2.0 & 1.6 & 1.2 & 1.5 & 1.5 \\
\hline $3-5$ & 7 & 1.5 & 1.5 & 1.7 & 1.9 & 1.8 & - & - & - & - \\
\hline $5-1$ & 8 & 3.0 & 3.2 & 2.7 & 3.2 & 3.1 & 3.0 & 3.1 & 2.4 & 2.4 \\
\hline $5-2$ & 9 & 3.0 & 2.7 & 3.9 & 3.4 & 4.2 & 4.1 & 3.8 & 3.3 & 3.2 \\
\hline $6-2$ & 10 & 2.3 & 1.5 & 3.0 & 3.4 & 2.6 & 1.4 & 2.7 & 2.2 & 2.0 \\
\hline $6-3$ & 11 & 2.2 & 2.0 & 2.1 & 2.2 & 3.2 & 1.8 & 1.0 & 1.7 & 2.7 \\
\hline $7-2$ & 12 & 1.3 & 1.2 & 0.9 & 1.2 & 1.3 & 1.6 & 1.2 & 1.4 & 1.4 \\
\hline $8-1$ & 13 & 2.9 & 1.8 & 3.3 & 3.2 & 3.2 & 2.3 & 2.1 & 1.3 & 1.0 \\
\hline $9-1$ & 14 & 1.6 & 2.0 & 1.9 & 1.5 & 3.8 & 1.4 & 2.2 & 1.1 & 1.8 \\
\hline A & & 2.2 & 2.1 & 2.4 & 2.6 & 2.8 & 2.7 & 2.3 & 2.2 & 2.3 \\
\hline
\end{tabular}

Sodium iodide was administered in aqueous solution subcutaneously as Hesse (7) showed that the results on nitrogen excretion are the same as when it is taken per os. This in itself is an indication that the liver is probably not primarily concerned in the mechanism of this action of iodides. One of our difficulties was in the irritating properties of the solution. The site of the injection in almost every case showed a sterile slough after a few days and evidently caused some discomfort to the animal, though we made the solution as 
dilute as possible without increasing the size of the injection mass beyond reasonable limits. However, the usual effect on the urinary nitrogen excretion was obtained. During the period in which the wound was open we could detect no effect on the nitrogen excretion. The dose administered was 100 mgm. per kilogram of dog once daily for three days. The total nitrogen in the urine was determined by the Kjeldahl method and total sulphur was determined by the method of Fiske (8). As soon as the dog was in positive nitrogen balance for three days the iodide was injected once a day for three days.

As will be seen from table 1 fourteen such experiments were done

TABLE 2

Shows the output of total sulphur in the urine of the same animals as those shown in table 1

Iodide injection on the fourth, fifth, and sixth days

\begin{tabular}{|c|c|c|c|c|c|c|c|c|c|c|}
\hline \multirow{2}{*}{$\begin{array}{l}\text { Animal } \\
\text { nun.ber }\end{array}$} & \multirow{2}{*}{$\begin{array}{c}\text { Experi- } \\
\text { ment } \\
\text { number }\end{array}$} & \multicolumn{9}{|c|}{ Day of experiment } \\
\hline & & 1 & 2 & 3 & 4 & 5 & 6 & 7 & 8 & 9 \\
\hline & & grams & grams & grams & grams & grams & grams & grams & grams & grams \\
\hline $5-1$ & 8 & 1.12 & 1.21 & 1.04 & 0.84 & 0.60 & 0.61 & 0.81 & 0.51 & 0.53 \\
\hline $5-2$ & 9 & 0.96 & 0.74 & 0.86 & 0.92 & 1.05 & 1.06 & 1.11 & 1.36 & 1.09 \\
\hline $6-2$ & 10 & 0.45 & 0.31 & 0.55 & 0.63 & 0.46 & 0.29 & 0.59 & 0.56 & 0.44 \\
\hline $6-3$ & 11 & 0.56 & 0.44 & 0.56 & 0.45 & 0.66 & 0.37 & 0.34 & 0.39 & 0.57 \\
\hline $7-2$ & 12 & 0.60 & 0.49 & 0.47 & 0.42 & 0.42 & 0.51 & 0.48 & 0.59 & 0.52 \\
\hline $7-3$ & 15 & 0.59 & 0.52 & 0.32 & 0.36 & 0.38 & 0.50 & 0.24 & 0.37 & 0.35 \\
\hline $8-1$ & 13 & 0.75 & 0.75 & 0.78 & 0.95 & 0.91 & 0.77 & 0.65 & 0.71 & 0.50 \\
\hline $9-1$ & 14 & 0.47 & 0.56 & 0.45 & 0.36 & 0.88 & 0.41 & 0.68 & 0.63 & 0.81 \\
\hline \multicolumn{2}{|c|}{ Average.. } & 0.70 & 0.63 & 0.63 & 0.62 & 0.67 & 0.57 & 0.61 & 0.64 & 0.60 \\
\hline
\end{tabular}

and on the average there is an increase of 27 per cent per day in the nitrogen excretion during the period in which sodium iodide was administered. Working this out statistically it is found that the mean daily excretion during the three days of the pre-iodide period is $2.2 \pm 0.103$. The mean excretion of the period of iodide administration is 2.6 grams and considering the P.E. of the mean of the preiodide period to be $2 \frac{1}{2}$ times the S.D., or $0.25 \mathrm{gram}$, it will be seen that this represents a real increase in nitrogen excretion dependent upon the drug alone.

From table 2 it will be seen that the total sulphur excretion remains constant during this period and does not increase with the nitrogen 
excretion. After one or more experiments of this type had been done on the dog a thyroidectomy was attempted. Hesse (7) has reported no difference in this action of iodides after the removal of the thyroid, although he states that his experiments were unsatisfactory due to the development of tetany in his dogs. Of those attempted, in two animals we successfully removed the thyroid and left behind sufficient parathyroid tissue so that the dog lived without tetany. The iodide injections were repeated under similar conditions

TABLE 3

Shows the daily twenty-four-hour urinary nitrogen output in the experiments after thyroidectomy

Figures in parentheses indicate the probable figure estimated from the urinary output. On most of these occasions it was observed that the animal urinated either just before or just after the moment of collection.

\begin{tabular}{|c|c|c|c|c|c|c|c|c|c|c|}
\hline \multirow{2}{*}{$\begin{array}{l}\text { Animal } \\
\text { number }\end{array}$} & \multirow{2}{*}{$\begin{array}{c}\text { Experi- } \\
\text { ment } \\
\text { number }\end{array}$} & \multicolumn{9}{|c|}{ Day of experiment } \\
\hline & & 1 & 2 & 3 & 4 & 5 & 6 & 7 & 8 & 9 \\
\hline & & grams & grams & grams & grams & grams & grams & grams & grams & grams \\
\hline $1-2$ & 16 & 3.4 & 3.2 & 3.0 & $\begin{array}{c}1.7 \\
(2.7)\end{array}$ & $\begin{array}{c}3.7 \\
(2.7)\end{array}$ & 3.4 & $\begin{array}{r}2.4 \\
(3.4)\end{array}$ & $\begin{array}{r}4.3 \\
(3.4)\end{array}$ & 2.7 \\
\hline $1-3$ & 17 & 3.6 & 3.3 & $\begin{array}{c}2.9 \\
(3.6)\end{array}$ & $\begin{array}{c}4.3 \\
(3.6)\end{array}$ & 3.7 & $\begin{array}{r}2.7 \\
(3.7)\end{array}$ & $\begin{array}{r}4.8 \\
(3.8)\end{array}$ & 4.0 & 3.8 \\
\hline $1-4$ & 18 & 2.8 & 2.3 & 4.1 & - & 2.6 & 3.4 & - & - & - \\
\hline $6-4$ & 19 & $\begin{array}{c}4.3 \\
(2.7)\end{array}$ & 2.4 & 2.2 & $\begin{array}{c}0.8 \\
(1.9)\end{array}$ & $\begin{array}{c}4.5 \\
(1.9)\end{array}$ & $\begin{array}{r}0.5 \\
(1.9)\end{array}$ & 2.1 & $\frac{-}{(2.7)}$ & $\begin{array}{r}5.4 \\
(2.7)\end{array}$ \\
\hline \multicolumn{2}{|c|}{ Average.. } & $\begin{array}{c}3.5 \\
(3.1)\end{array}$ & 2.8 & $\begin{array}{c}3.1 \\
(3.2)\end{array}$ & $\begin{array}{c}2.3 \\
(2.7)\end{array}$ & $\begin{array}{c}3.6 \\
(2.7)\end{array}$ & $\begin{array}{r}2.5 \\
(3.1)\end{array}$ & $\begin{array}{r}3.1 \\
(3.1)\end{array}$ & $\begin{array}{r}4.1 \\
(3.4)\end{array}$ & $\begin{array}{r}4.0 \\
(3.1)\end{array}$ \\
\hline
\end{tabular}

as before thyroidectomy and under these circumstances no increase in the nitrogen excretion occurred. Sulphur excretion was not determined in these experiments. This is shown in table 3.

The results are depicted graphically in the accompanying charts. It is evident from these experiments that in dogs on a constant diet the injection of sodium iodide causes an increase in the nitrogen excretion in the urine. This increase in nitrogen excretion is not accompanied by a diuresis nor by an increase in the total sulphur 
excretion. During the period of increased nitrogen elimination the concentration of the urine changes. These effects are absent if the thyroid is removed. Figure 2 shows the effect of sodium iodide on

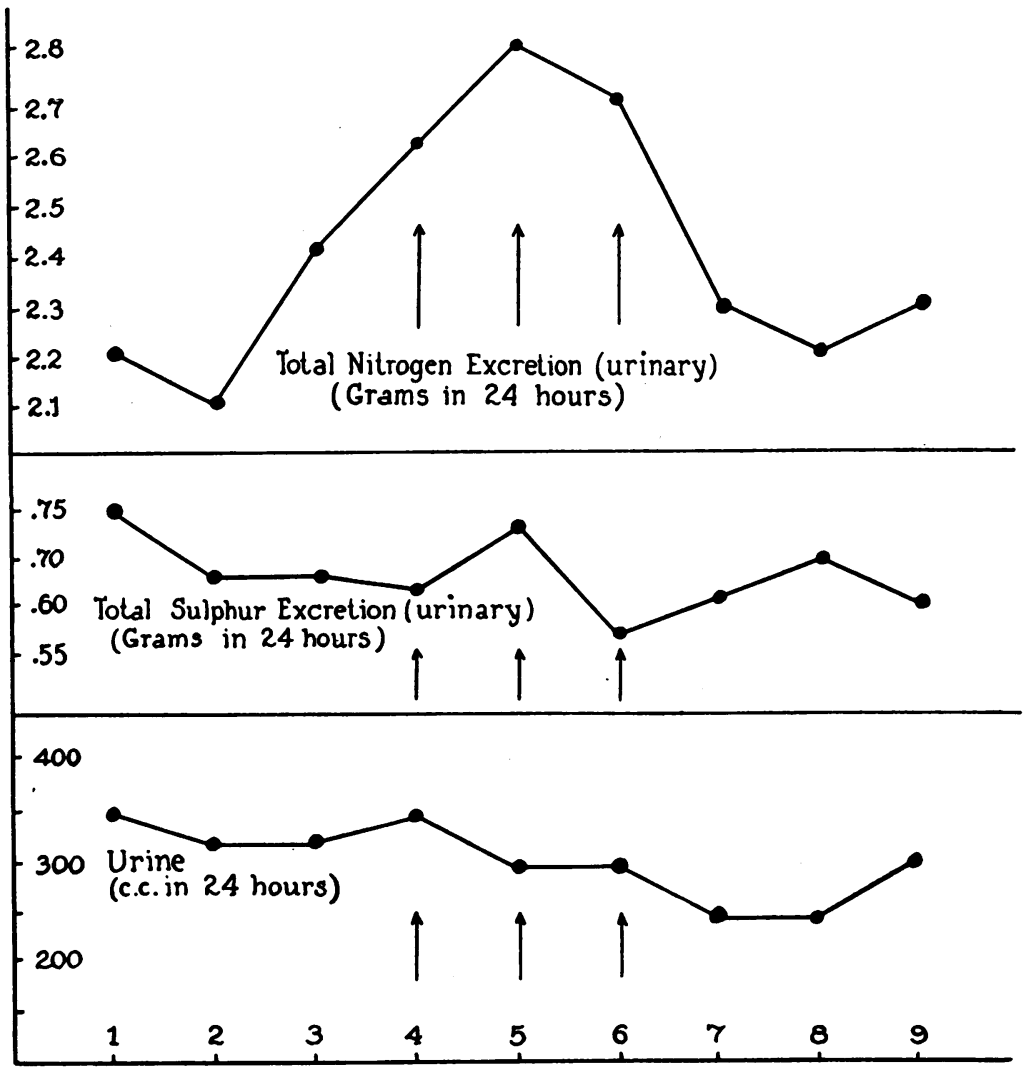

Fig. 1. Shows the Mean Excretion of 14 Experiments Listed in Tables 1 aNd 2

Note that the output of urine remains essentially constant. The arrows indicate the three days on which the iodide was injected.

the nitrogen excretion in the same animals before and after removal of the thyroid gland.

The source of this nitrogen must be a matter of speculation. That this is the same nitrogen described by Lusk (9) as "deposit nitrogen" which he states is "poor in sulphur" seems likely. However, the existence of deposit nitrogen is still denied by some observers though 
it must be admitted that there is some nitrogen stored in the body. It is evident from these experiments that the thyroid must be present for sodium iodide to produce the effect described. From this it may be inferred that the thyroid plays some part in the metabolism of this nitrogen. This function appears to be separated from the effect

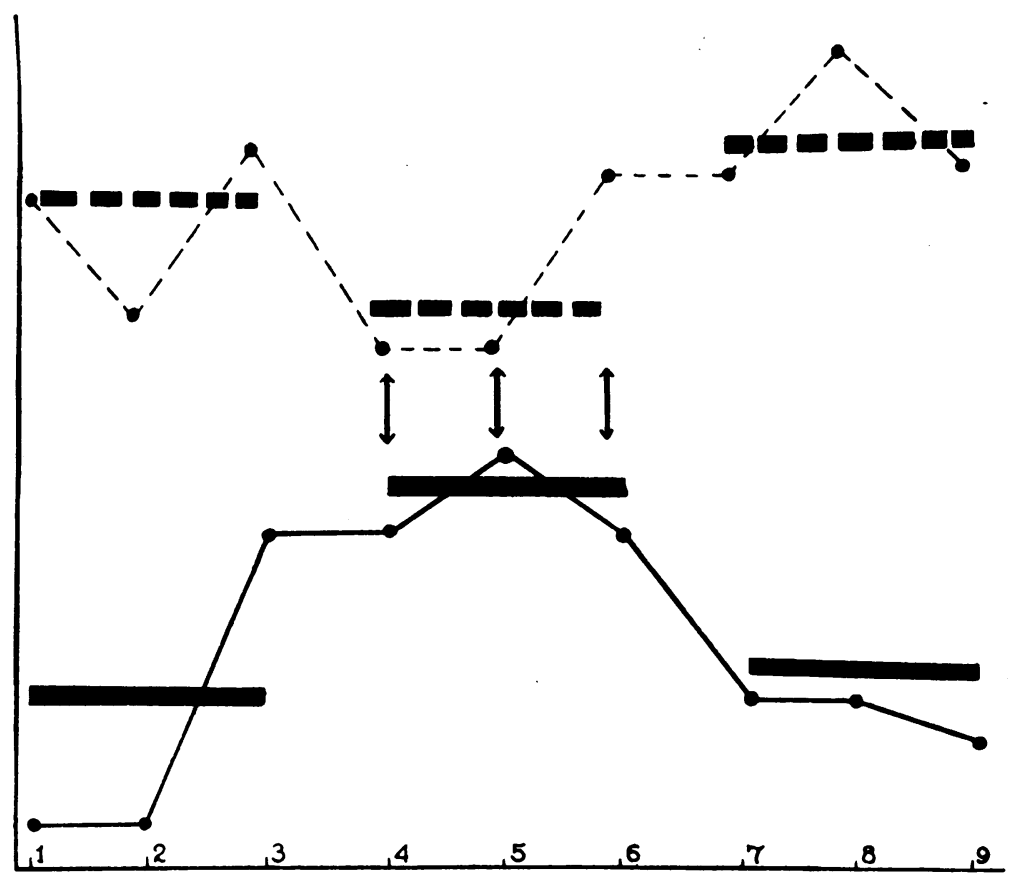

FIG. 2

The upper dotted line shows the urinary nitrogen excretion of dogs after thyroidectomy. The lower solid line shows the urinary nitrogen excretion of the same dogs before thyroidectomy. Arrows indicate the three days of iodide administration. The heavy dotted and heavy solid lines indicate the mean level of nitrogen excretion for the preiodide, iodide, and postiodide periods of three days each.

of the thyroid on the basal metabolism as it has been shown (10) that iodides cause no change in the basal metabolic rate in normal subjects. In certain types of hypothyroidism mucinous substances are believed to be accumulated under the skin. Inasmuch as the mucins are nitrogenous substances containing no sulphur the rôle of the thyroid in these experiments seems corroborative of the findings in myxedema. As soon as the occasion presents itself it is planned to check these findings by the study of a case of myxedema. 


\section{SUMMARY AND CONCLUSIONS}

1. A 27 per cent increase in the daily nitrogen excretion of dogs on a constant diet followed the subcutaneous injection of a solution of sodium iodide.

2. This increase in nitrogen excretion was not accompanied by an increase in sulphur excretion.

3. The fluid intake and urine output were both maintained on a constant level throughout these experiments.

4. It seems likely that this increase in nitrogen excretion without a corresponding increase in sulphur excretion represents a mobilization and excretion of "deposit nitrogen."

5. The increase of nitrogen excretion following the injection of sodium iodide did not occur after the removal of the thyroid gland in two dogs.

6. It seems evident that the presence of the thyroid gland is necessary for the mobilization and excretion of this nitrogen following the administration of iodides.

7. It is suggested that the thyroid may have as one of its functions (apart from its effect on the basal metabolism) the mobilization of "deposit nitrogen" poor or lacking in sulphur.

\section{BIBLIOGRAPHY}

1. Samoiloff, S., Sbornik Rabot Proiswedennich Laboratory V. K. Anrepa, 1885-1886, i, 27.

2. Sollmann, T., J. Pharm. and Exp. Therap., 1919, xiii, 495. Iodin: Effect on Fibrous Nodules.

3. Jobling, J. W., and Petersen, W., Arch. Int. Med., 1915, xv, 286. The Therapeutic Action of Iodin.

4. Grabfield, G. P., Alpers, B. J., and Prentiss, A. M., J. Pharm. and Exp. Therap., 1923, xxii, 393. The Effect of Iodides on Nitrogen Metabolism.

5. Grabfield, G. P., and Prentiss, A. M., J. Pharm. and Exp. Therap., 1926, xxvii, 231. Effect of Iodides on the Nitrogen Partition.

6. Grabfield, G. P., and Prentiss, A. M., J. Pharm. and Exp. Therap., 1925, xxv, 411. Further Studies on the Effect of Iodides on the Human Nitrogen Metabolism.

7. Hesse, E., Arch. f. Exp. Path. u. Pharm., 1924, cii, 63. Die Stoffwechselwirkung der Jodalkalien.

8. Fiske, C. H., J. Biol. Chem., 1921, xlvii, 59. The Determination of Inorganic Sulfate, Total Sulfate and Total Sulfur in Urine by the Benzidine Method.

9. Lusk, G., The Science of Nutrition, N. Y., 1923.

10. Boothby, W. M., and Rowntree, L. G., J. Pharm. and Exp. Therap., 1923, xxii. 99 Drugs and Basal Metabolism. 